they may show, should shed much light on the regulation of endocrine cycles in the lower vertebrates.

Dr. G. W. Harris (London), who thoughtfully made it a condition of his appearance that he would not have to write a paper, dealt comprehensively with comparative aspects of the functional relationships of the hypothalamus and adenohypophysis. He paid a graceful tribute to the pioneer work of the late F. H. A. Marshall in the field of reproduction physiology.

The final two papers were concerned with invertebrates. Dr. M. J. Wells (Cambridge) gave an account of some of his work on the optic glands and the ovary of Octopus and described a hormonal system which regulates the onset of sexual maturity. In cephalopods, maturation of the gonad depends upon release of a protein secretion from the optic glands. These are in turn governed by an inhibitory nerve supply originating in the highest centres of the central nervous system. The optic glands can be activated (causing precocious sexual maturity) by severance of this nerve supply, or by peripheral blinding. 'Ripening' of the oviducts and oviducal glands is independent of ovarian maturation. The system is single-stage; the state of these secondary structures is not under the control of sex hormones. The brain -optic gland system of cephalopods has obvious analogues in chordates and arthropods; the factors determining the convergent evolution of mechanisms for delaying the onset of sexual maturity were discussed.

The final paper was by Dr. D. B. Carlisle (Plymouth) on moulting cycles in Crustacea. The act of moulting in arthropods, said Dr. Carlisle, must not be considered as an isolated event but as the most spectacular moment in a continuous cycle of meta. bolic activity. Each moulting cycle is basically like the one before it, and many of the stages have now been shown to be under hormonal control. Secretion of the 'moult inhibiting hormone' by the endocrine complex of the eye-stalk promotes the formation of new tissues and prevents the $Y$ organ from secreting more than 'marginal' amounts of its hormone. Once this eye-stalk hormone ceases to be stecreted the $Y$ organ releases a single 'dose' of a moult-promoting hormone. This initiates the preparations for the moult which, once under way, are co-ordinated by a moult-accelerating hormone from the $X$ organ. The amount of water taken in at the moult itself is regulated by a further eye-stalk hormone. Many other hormones act upon particular moults and modify them in some way, acting mainly upon the stage of proecdysis and making the succeeding moult in some way unique : the moult of puberty and the moult at which a female becomes furnished with the brooding characters are examples. In the same way that the originally similar segments of the vertebrate body have been progressively and uniquely modified (in, for example, the head) so the originally similar moults of arthropods have been modified, until we have what Dr. Carlisle called 'the startling difference' between the larval and imaginal moults of Lepid. optera.

Prof. J. Z. Young, who was chairman of the invertebrate session, enlarged upon a statement made by the final speaker concerning the complications of modern endocrinology. Prof. Young said that the presence of a multiplicity of hormones was the natural consequence of the fact that they were sent out, broadcast through the body and each needed to be addressed to a particular target. No such multiplicity of chemical mediators was necessary in the nervous system, where addresses were specified by connexions. The discovery of more and more distinct hormones was a sign of the maturity of the subject. Endocrinologists were learning to understand the code with which their complicated system operated.

The symposium concluded with a general discussion and a summary by Sir Solly Zuckerman. The papers will be published soon as one of the Symposia of the Zoological Society of London. A. J. MARSHALL

\title{
AERODYNAMIC CAPTURE OF PARTICLES
}

A SYMPOSIUM on this subject was held during January 13-14 in the laboratories of the British Coal Utilization Research Association at Leatherhead.

Although this might be thought to be a field of very limited appeal, yet, as evidenced by the wide interests of the fifty scientists present, the impingement of small particles carried in a stream of air and falling on to a solid surface placed alongside or in the way of the flow is a problem which concerns a number of industries, as well as having moteorologieal implications ranging from the ieing of aireraft wings and motor-car windscreens to defence against microbiological warfare.

The wide scope of the applications of this study can be seen by looking through the list of titles offered at this symposium. In 'pure' meteorology one studies cloud formation and collision of raindrops, in applied meteorology the wash-out by rain of particulate matter, whether this be the product of industrial air pollution or of an atomic explosion. A number of cognate problems arise in the laying of mine dusts by water sprays. Then we have the impact of water drops or ice crystals on large moving surfaces such as aircraft wings or turbine blades; when both the obstacle and particles are on a smaller scale we have the action of the gas-mask filter (one of the earliest applications).

The coagulation of particles carried by a strearn of air or water is, of course, of great interest and involves many applications where solid or liquid particles have to be transported from place to place, for example, in the industrial process of fluidization.

The basic theory of much of this work stems from Albrecht, who worked out in 1931 the proportion of particles carried by a stream of air which would be intercepted by a cylinder placed athwart the stream. The particles tend to follow the stream lines as they approach the cylinder, but their mass makes them continue in a forthright direction. If their resistance in the stream is given by Stokes's law, that is, direct proportionality to velocity and viscosity, their actual paths depend on this balance between inertia and viscosity in a parameter resembling a particle Reynolds number. This 'particle parameter' has been 
used continually in capture problems since (and deserves the attribution of Albrecht number).

The conference, opened by a short address of welcome from Dr. Idris Jones, director of research of the National Coal Board, was divided into three sessions. The first morning covered fundamental aspects, a number of developments of the Albrecht thesis, using modern mathematical devices and including other types of flow around the obstacle than the potential one (H. Herne). Prof. P. R. Owen had devoted a considerable study to the process by which a turbulent wind-stream deposits particles on the roof of a tunnel, while Dr. D. J. Brown had studied the behaviour of particles in the process of froth flotation. Dr. T. Gillespie, who had come from the United States to attend the symposium, described his interesting series of researches on the role of electric forces in collision processes.

The afternoon session was devoted to practical applications of capture techniques. Accounts were given of the deposition experiments on radioactive particles and gases carried out at the Atomic Energy Research Establishment (A. C. Chamberlain); on particulate filters-one of the earliest applicationsat the Chemical Defence Experimental Establishment (R. G. Dorman); on fish-curing smokes at the Herring Industry's Research Station (W. W. Foster) and two applications in the aircraft industry, namely, impingement of water drops on a surface at super. sonic speeds (D. C. Jenkins and J. D. Booker) and on turbine blades (D. L. Martlew).

In the final session the papers dealt with collisions of particles with rain-drops, and of drops with each other. The difficult calculations on the relative motions of particles of comparable size-when the flow pattern around each contestant must be knownhad been made by Dr. L. M. Hocking; but other papers were primarily experimental. A long and careful series of experiments by W. Walton and A. Woolcock and less-extensive ones by Dr. R. G. Picknett involved the measurement of the pick-up by a single water drop on which small particles impacted. Finally, the effect of the efficiency of the pick-up process when the particles are wettable and can be engulfed or pass completely through the water drop was diseussed both theoretically (by C. S. Pemberton) and experimentally (by B. Oakes).

At the conclusion of the third session, $\mathrm{Mr}$. W. Walton (National Coal Board) thanked the staff of British Coal Utilization Research Association for offering the symposium the hospitality of its conference rooms and laboratories, the work in which the visitors were able to inspect before leaving.

Lively discussions followed the reading of the papers. The whole proceedings are to be published by Pergamon Press, Ltd. and should form an interesting volume in a field which has not been heretofore covered by a book.
E. G. Richardson

\title{
THE SHUTTLE-BOX BEHAVIOUR OF ALBINO RATS DURING PROLONGED EXPOSURE TO MODERATE-LEVEL RADIATION
}

\author{
By Dr. JOHN E. OVERALL*, Dr. W. LYNN BROWN $\dagger$ and Dr. LOREN C. LOGIE \\ The Radiobiological Laboratory, University of Texas, and the United States \\ Air Force, Austin, Texas
}

\begin{abstract}
HIS series of investigations was commenced in an effort to test conclusions reached by other investigators ${ }^{1,2}$ that radiation is a 'noxious stimulus' capable of resulting in avoidance conditioning. In three independent attempts to reproduce 'spatial conditioned avoidance' at this Laboratory, no success was obtained. In each of these experiments, albino rats were on alternate days exposed to $1 \mathrm{r}$. per min. of X-radiation while confined in a black compartment. During subsequent test periods, the rats were given free access to black and white shuttle-box compartment. No significant avoidance of the black compartment was observed in any of the three experiments when the behaviour of the experimental subjects was compared with that of control subjects.

Although no 'conditioned avoidance' was observed in the initial experiments, it could not be concluded that rats are unable to perceive radiation. A more sensitive procedure would seem to be one that allows rats to choose between two shuttle-box compartments

* Chief, Criterion Development Service, Central N.P. Research Laboratory, Veterans Administration Hospital, Perrypoint, Maryland. This collaborator is indebted to the National Science Foundation through its Postdoctoral Fellowship Program for making possible continued collaboration on this project.

+ Department of Psychology, University of Texas, Austin, Texas. $\ddagger$ Captain, U.S.A.F., School of A viation Medicine, Brooks Air Force Base, Texas.
\end{abstract}

-one located in a radiation field and the other shielded from radiation by a lead screen. Because rats normally prefer the darker of two compartments, it was considered appropriate to use shuttle-boxes with one dark and one light compartment and to place the darker compartment in the exposed area. Dose-rates of $0,1,2$ and $4 \mathrm{r}$. per min. were employed in this experiment. The results clearly indicated that the experimental animals spent less than a normal amount of time in the usually preferred darker compartment. It was concluded that the presence of radiation in a normally preferred surrounding results in reduced preference for that surrounding; however, no conclusion concerning the nature of the mechanism responsible for the change was possible. Did the rats perceive the radiation, or its immediate consequences, and associate it with the black compartment? Did physiological ehanges resulting from the radiation produce stimuli which simply overshadowed the normal preference for the dark compartment?

A new experiment was designed which was like the preceding one except that it involved three groups : (a) 'radiation experimental' with exposure in the darker compartment and no exposure in the lighter compartment; (b) 'non-radiation control' with no exposure in either compartment, and $(c)$ 'radiation control' with exposure in both the lighter and darker 